\title{
Detergent-induced cell aggregation in subpopulations of Pseudomonas aeruginosa as a preadaptive survival strategy
}

\author{
Janosch Klebensberger, ${ }^{1}$ Karin Lautenschlager, ${ }^{1}$ \\ Daniel Bressler, ${ }^{2}$ Jost Wingender ${ }^{2}$ and \\ Bodo Philipp ${ }^{1 *}$ \\ ${ }^{1}$ Universität Konstanz, Fachbereich Biologie, Mikrobielle \\ Ökologie, Fach M654, 78457 Konstanz, Germany. \\ ${ }^{2}$ Universität Duisburg-Essen, Biofilm Centre, \\ Geibelstrasse 41, 47057 Duisburg, Germany.
}

\section{Summary}

During growth of Pseudomonas aeruginosa strain PAO1 with the toxic detergent SDS, a part of the population actively formed macroscopic cell aggregates while the other part grew as freely suspended cells. The physiological function of aggregation for growth with SDS was investigated. Three mutants growing with SDS without aggregation were isolated: the spontaneous mutant strain $\mathrm{N}$ and two mutants with transposon insertions in the psl operon for exopolysaccharide synthesis. SDS-induced aggregation in strain $\mathrm{N}$ but not in a ps/J mutant was restored by complementation with two genes encoding diguanylate cyclases responsible for synthesis of cyclic-di-guanosine monophosphate (c-di-GMP). By expressing a c-di-GMP-specific phosphodiesterase SDS-induced aggregation of strain PAO1 was reduced. Upon exposure to SDS in the presence of the uncoupler carbonyl cyanide chlorophenylhydrazone, the aggregating strains had ca. 500-fold higher survival rates than the non-aggregating strains. Co-incubation experiments revealed that strain $\mathrm{N}$ could integrate into aggregates of strain PAO1 and thereby increase its survival rate more than 1000 -fold. These results showed that SDS-induced aggregation involved c-di-GMP signalling with the ps/operon as a possible target. Cell aggregation could serve as a pre-adaptive strategy ensuring survival and growth of $P$. aeruginosa populations in environments with multiple toxic chemicals.

${ }^{*}$ For

correspondence. E-mail bodo.philipp@uni-konstanz.de; Tel. (+49) 7531 884541; Fax (+49) 7531884047.

\section{Introduction}

The ubiquitous bacterium Pseudomonas aeruginosa is characterized by a great metabolic versatility (Clarke, 1982 ) and a high adaptability to cope with different environmental stress factors (Rodrigue et al., 2000). These traits support its successful colonization of hostile anthropogenic environments where it encounters toxic organic substances, such as detergents and disinfectants, some of which can be utilized as growth substrates. Examples for such environments are industrial wastewaters and healthcare settings where $P$. aeruginosa is a major cause for hospital infections (Emori and Gaynes, 1993). Sinks for disposal of disinfectants and detergents have been repeatedly identified as environmental sources of several $P$. aeruginosa outbreaks in clinical settings (Muscarella, 2004). Understanding survival and growth strategies of $P$. aeruginosa is thus a feasible approach for developing effective measures to prevent the establishment of this opportunistic pathogen in anthropogenic environments.

Recently, we have reported that $P$. aeruginosa strain PAO1 can grow with the anionic detergent SDS (Na-dodecylsulfate) as sole source of carbon and energy (Klebensberger et al., 2006). At the same time the alkyl sulfatase SdsA, which catalyses the first step of SDS degradation in $P$. aeruginosa, was identified and characterized (Hagelueken et al., 2006). SDS is a common ingredient of many household products and very toxic to bacteria because it damages membranes and proteins (Helenius and Simons, 1975). Bacteria require energydependent resistance mechanisms such as efflux pumps and Clp-proteases for growing in the presence of detergents (Rajagopal et al., 2002; Poole, 2004). We have shown that SDS was also toxic for strain PAO1 and that surviving of SDS exposure required energy (Klebensberger et al., 2006). If SDS is used for growth, the cells have to find a trade-off for energy investment: to generate energy for growth, they have to uptake SDS, thereby risking to be injured. For protection and repair, they have to invest part of this energy which is consequently not available for growth. This dilemma calls attention to further adaptive strategies that allow growth with a toxic compound as sole source of carbon and energy. We reported that strain PAO1 formed macroscopic cell 
aggregates as an active, energy-requiring stress response to SDS. The formation of cell aggregates or biofilms is an important adaptive strategy of $P$. aeruginosa and other bacteria to colonize adverse environments because residing in such structures confers increased resistance to biocides such as antibiotics, disinfectants and detergents (Lewis, 2001; Gilbert et al., 2002; Drenkard, 2003; Fux et al., 2005).

The formation of cell aggregates or biofilms requires the production of extracellular polymeric substances (EPS). The EPS of $P$. aeruginosa biofilms have been shown to contain DNA (Whitchurch et al., 2002; Steinberger and Holden, 2005; Allesen-Holm et al., 2006) and different polysaccharides (Linker and Jones, 1964; Friedman and Kolter, 2004; Tielen et al., 2005; Ude et al., 2006). The EPS of the macroscopic aggregates formed by strain PAO1 during growth with SDS contained acidic polysaccharides and DNA (Klebensberger et al., 2006). By treatment with DNase, these aggregates were disintegrated and viable cells were released. The formation of cell aggregates and biofilms in $P$. aeruginosa and other bacteria has been shown to involve cyclic-di-guanosine monophosphate (c-di-GMP) signalling (Römling et al., 2005; Jenal and Malone, 2006). This intracellular second messenger molecule was originally found in Gluconacetobacter xylinus where it acts as an allosteric regulator of cellulose synthase (Ross et al., 1986). Cyclic-diguanosine monophosphate biosynthesis from two GTP is catalysed by diguanylate cyclases (DGCs) containing a characteristic GGDEF domain as the active centre (Chan et al., 2004; Ryjenkov et al., 2005). The hydrolysis of c-diGMP is catalysed by specific phosphodiesterases (PDEs) containing either an EAL or a HD-GYP domain (Christen et al., 2005; Ryan et al., 2006). Pseudomonas aeruginosa harbours 17 genes with a GGDEF domain, six genes with an EAL domain and 14 genes containing both domains (Kulesekara et al., 2006). A function in cell aggregation or biofilm formation has been demonstrated only for a few of them so far (D'Argenio et al., 2002; Drenkard and Ausubel, 2002; Hickman et al., 2005; Hoffman et al., 2005).

We proposed that aggregate formation of strain PAO1 is a survival strategy for growth with the toxic detergent SDS. This hypothesis was supported by the fact that aggregated cells of strain PAO1 had a more than 100-fold higher survival rate than freely suspended cells if exposed to SDS in the presence of a second toxic compound, carbonyl cyanide chlorophenylhydrazone (CCCP), which deprives the cells of energy by dissipating the proton motive force (Klebensberger et al., 2006). However, in the cultures growing with SDS, the cells were not homogeneously distributed as they grew in aggregates and as freely suspended cells. This observation forces the question for the exact physiological role of cell aggregation during growth with SDS. As aggregate formation strictly preceded growth of suspended cells, we hypothesized that cell aggregation is important for initiating growth of strain PAO1 with SDS. If cell aggregation would not be essential for growth with SDS, it should be readily lost because it is carbon- and energy-requiring. In this case non-aggregating mutants would arise and successfully compete against cells that maintain the aggregative phenotype. If cell aggregation is essential such nonaggregating mutants should not arise unless they are more resistant to SDS. Attempts to isolate spontaneous non-aggregating mutants of $P$. aeruginosa strain PAO1 were the starting point of our study to define the physiological role of cell aggregation during growth with the toxic detergent SDS.

\section{Results}

\section{Isolation and characterization of strain $\mathrm{N}$}

To investigate whether spontaneous non-aggregative mutants of strain PAO1 would enrich in liquid cultures, freely suspended cells from cultures growing with SDS in the early logarithmic phase were repeatedly transferred into fresh medium. After 15 transfers we obtained a culture that contained only few and small aggregates. From this culture, aliquots were spread on solid M9 medium with SDS as carbon and energy source. We observed different colony morphologies, namely rough and highly structured colonies as well as smooth, soft and unstructured colonies. The parental strain PAO1 formed rough colonies on SDS-containing agar plates (Fig. 1, B1) and cell aggregates during growth with SDS in liquid culture (Fig. 1, C1). With succinate as carbon and energy source, strain PAO1 formed smooth colonies on agar plates (Fig. 1, A1) and did not aggregate in liquid cultures (not shown). One strain forming smooth colonies on SDScontaining agar plates, strain $\mathrm{N}$, was characterized further. Strain $N$ formed smooth colonies irrespective of the substrate (Fig. 1, A2 and B2) and did not aggregate in liquid cultures with SDS (Fig. 1, C2). This phenotype was stable without the appearance of revertants after several passages in media without SDS. Therefore, we consider strain $\mathrm{N}$ as a spontaneous mutant of strain PAO1 that does not aggregate during growth with SDS.

Strain $\mathrm{N}$ reached a higher $\mathrm{OD}_{600}$ than the suspended cells of strain PAO1 (Fig. 2A) but their molar growth yields did not differ significantly $[Y=163 \pm 16 \mathrm{~g}$ dry mass

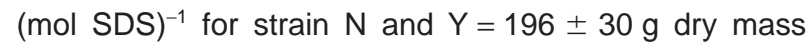
$(\mathrm{mol} \mathrm{SDS})^{-1}$ for strain PAO1]. The growth rate of strain $\mathrm{N}$ with SDS $\left(\mu=0.395 \mathrm{~h}^{-1}\right)$ was higher than the growth rate of those cells of strain PAO1 that grew in suspension $\left(\mu=0.3081 \mathrm{~h}^{-1}\right)$. To test whether the increased growth rate of strain $\mathrm{N}$ was caused by a higher specific activity of 
1

a)

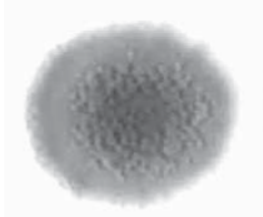

b)

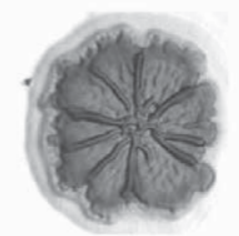

c)

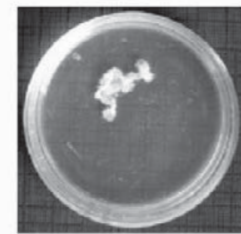

d)

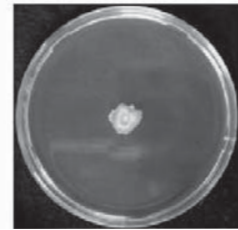

2
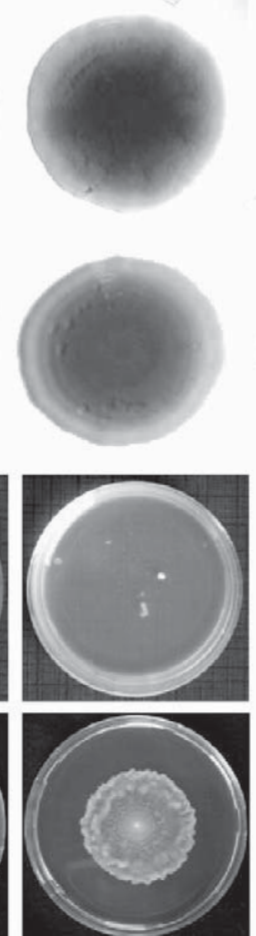

3
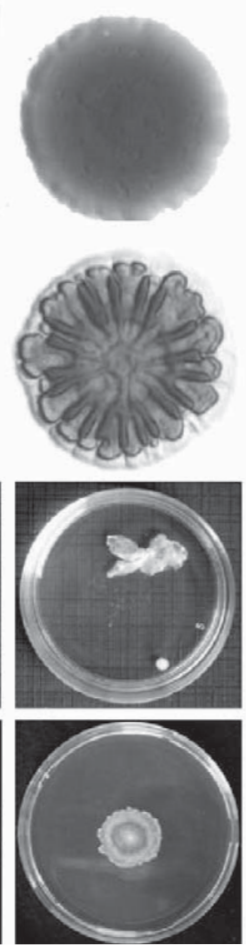

4
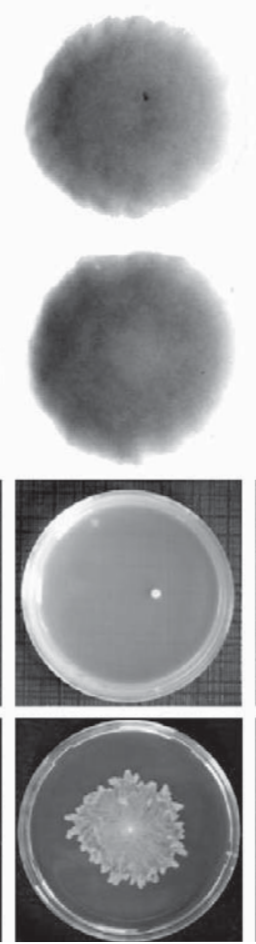

5
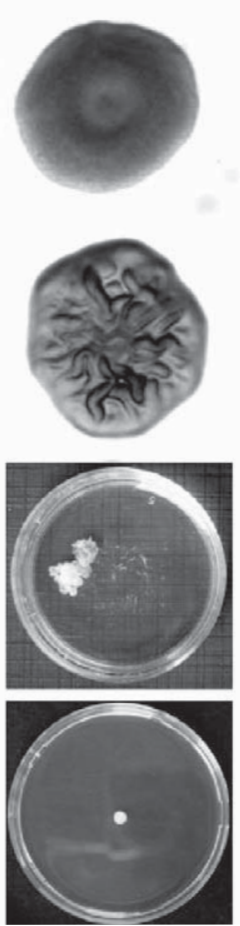

6
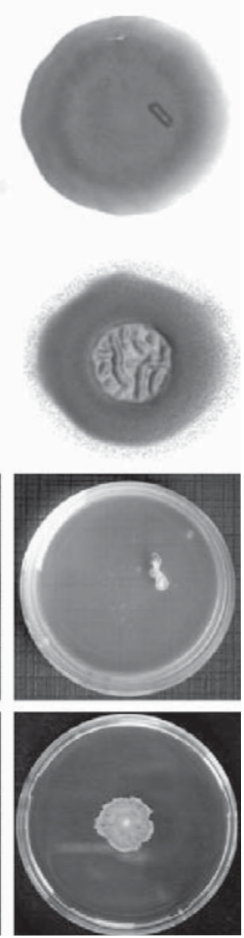

Fig. 1. Characterization of different $P$. aeruginosa strains.

A. Colony morphology on $\mathrm{M} 9$ containing $10 \mathrm{mM}$ succinate after incubation for 1 day at $37^{\circ} \mathrm{C}$.

B. Colony morphology on M9 containing $0.15 \%$ SDS after incubation for 3 day at $37^{\circ} \mathrm{C}$.

C. Growth in liquid M9 medium containing $0.1 \%$ SDS after incubation for $18 \mathrm{~h}$ at $30^{\circ} \mathrm{C}$ with shaking at 120 r.p.m.

D. Swarming motility on semi-solid agar after incubation for $24 \mathrm{~h}$ at $37^{\circ} \mathrm{C}$.

The different strains are indicated by the following numeration: (1) PAO1 pUCP18, (2) N pUCP18, (3) N pUCP18[4929], (4) PAO1-D4 pUCP18, (5) PAO1 pBBR, (6) PAO1 pBBR[CC3396].

enzymes involved in SDS degradation we determined the activity of SDS-alkyl sulfatase. The specific activities of SDS alkyl sulfatase in cell-free extracts of both strains were not significantly different $\left(25 \pm 3 \mathrm{mU} \mathrm{mg}^{-1}\right.$ protein for strain $\mathrm{N}$ and $31 \pm 3 \mathrm{mU} \mathrm{mg}^{-1}$ protein for strain PAO1).
During growth with SDS, strain PAO1 produced about $50 \%$ more pyocyanine than strain N (Fig. 2B). As a further difference, strain $\mathrm{N}$ had a higher swarming motility than strain PAO1 (Fig. 1, D1 and D2) whereas no differences were observed in swimming motility (not shown). a)

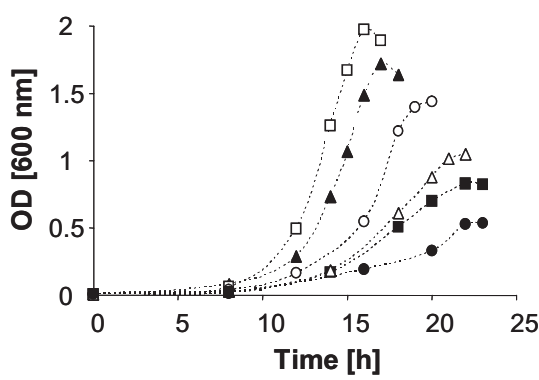

b)

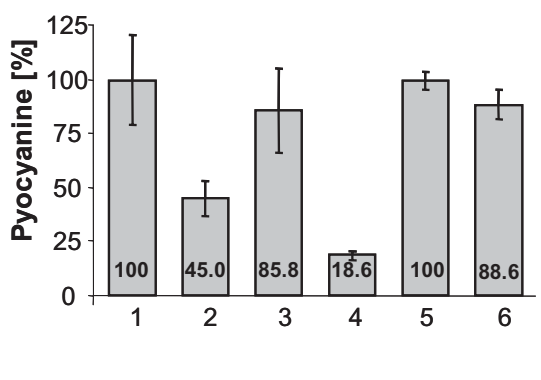

Fig. 2. Growth and pyocyanine production of different $P$. aeruginosa strains in $\mathrm{M} 9$ medium containing $3.5 \mathrm{mM} \mathrm{SDS}$ at $30^{\circ} \mathrm{C}$ with shaking at 200 r.p.m.

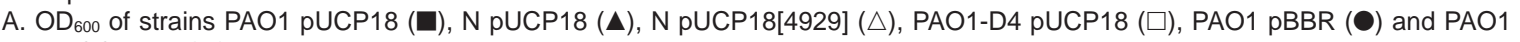
pBBR[CC3396] (O).

B. Percentages of pyocyanine produced by the individual strains normalized to pyocyanine production of strain PAO1 pUCP18 (100\%). The different strains are indicated by the following numeration: (1) PAO1 pUCP18, (2) N pUCP18, (3) N pUCP18[4929], (4) PAO1-D4 pUCP18, (5) PAO1 pBBR, (6) PAO1 pBBR[CC3396]. Error bars indicate standard deviation $(n=3)$. 


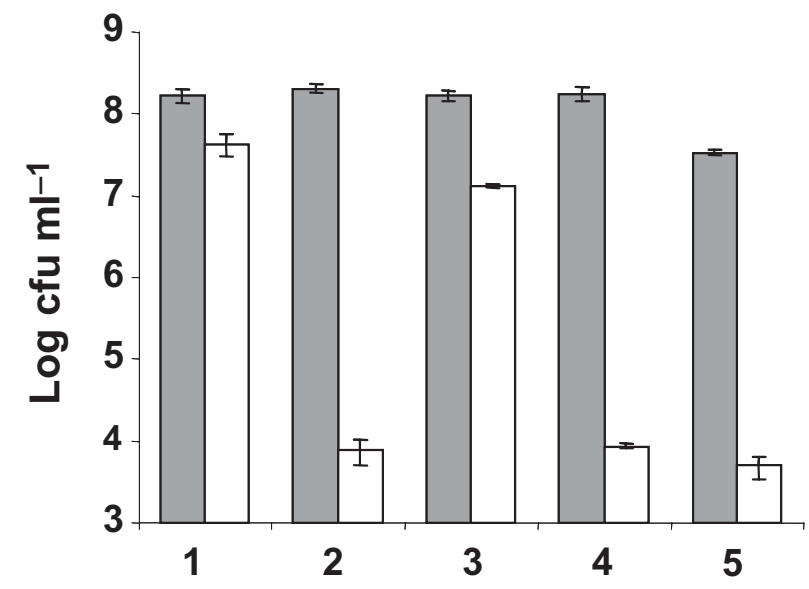

Fig. 3. Survival of different $P$. aeruginosa strains after exposure to $3.5 \mathrm{mM}$ SDS in the absence (grey bars) or in the presence (white bars) of $1 \mathrm{mM}$ CCCP determined as cfu counts. The different strains are indicated by the following numeration: (1) PAO1 pUCP18, (2) N pUCP18, (3) N pUCP18[4929], (4) PAO1-D4 pUCP18, (5) PAO1 pBBR[CC3396]. Error bars indicate standard deviation $(n=3)$.

To investigate whether strain $\mathrm{N}$ was more resistant to SDS, we submitted it to the same shock experiments as described previously for strain PAO1 (Klebensberger et al., 2006). In cell suspensions of strain N, SDS $(3.5 \mathrm{mM})$ caused a decrease in $\mathrm{OD}_{600}$ and cfu counts as well as a release of DNA and protein into the medium (not shown). These responses to SDS were indistinguishable from the responses of suspended cells of strain PAO1. As also observed earlier with strain PAO1, energy limitation by addition of $\mathrm{KCN}(2 \mathrm{mM})$ prevented all responses to SDS (not shown) whereas complete deprivation of energy by the addition of CCCP $(1 \mathrm{mM})$ in the presence of SDS caused a rapid and complete lysis of the cells (Fig. 3). These results gave no indication that strain $\mathrm{N}$ was more resistant to SDS than suspended cells of strain PAO1. The only striking difference in these SDS shock experiments was that strain PAO1 formed macroscopic aggregates whereas strain $\mathrm{N}$ did not.

\section{Restoration of SDS-induced aggregation in strain N by complementation}

To investigate whether SDS-induced aggregation could be genetically restored in strain $\mathrm{N}$, we transformed strain $\mathrm{N}$ with a genomic library of strain PAO1 in pUCP18 and screened for clones with rough colony morphology on SDS containing agar plates. Among 6000 transformants we found 28 rough colonies. These were further tested for SDS-induced aggregation in liquid culture. Ten of these clones formed macroscopic aggregates during growth with SDS. Sequence analysis revealed that six out of 10 complementing plasmids harboured genomic fragments that included genes with a GGDEF motif. In particular, these complementing fragments contained genes for the putative DGCs PA1107 (neighboured by PA1106 and fliJ), PA1727 (neighboured by PA1728 and PA1729) and PA4929 (neighboured by alr). Further subcloning of these three putative DGC genes as single genes (Table 1) revealed that they were responsible for complementation in strain $\mathrm{N}$.

To investigate whether the formation of macroscopic aggregates by these complemented clones of strain $\mathrm{N}$ was SDS-dependent or a constitutive phenotype caused by overexpression of DGCs, we compared their phenotypes during growth with SDS and with succinate. Strains $\mathrm{N}$ pUCP18[1107] (not shown) and N pUCP18[4929] formed rough colonies on agar plates and macroscopic aggregates in liquid medium only with SDS but not with succinate as carbon and energy source (Fig. 1, A3-C3). In contrast, strain N pUCP18[1727] formed rough colonies and macroscopic aggregates also during growth with succinate (not shown). Swarming motility, growth curves and pyocyanine production of strain N pUCP18[1107] (not shown) and of strain N pUCP18[4929] resembled those of the parental strain PAO1 (Fig. 1, D3; Fig. 2). The macroscopic aggregates formed by strain $\mathrm{N}$ complemented with pUCP18[1107] or pUCP18[4929] were indistinguishable from aggregates of strain PAO1.

To check if strain $\mathrm{N}$ carried mutations in the genes PA1107, PA1727 or PA4929, we amplified them with the primers indicated in Table 2 and sequenced them. No mutation could be detected compared with the corresponding sequences in Pseudomonas Genome Project database. We also constructed insertion mutants of strain PAO1 in each of the three genes. These insertional inactivations did neither change the SDS-dependent formation of rough colonies on agar plates nor the SDS-induced cell aggregation in liquid culture.

Two of the four remaining complementing plasmids contained fragments of about $1200 \mathrm{bp}$ with the single gene PA1869 which encodes a putative acyl carrier protein (KN2C and NNG1, Table 1). The other two complementing plasmids carried a fragment of about 3900 bp containing the genes $p v c B C D$ (KN6B and KN7C, Table 1). Sequence analysis of these genes in strain $N$ revealed no mutations compared with the corresponding sequences in Pseudomonas Genome Project database.

\section{Expression of a PDE from Caulobacter crescentus in strain PAO1}

The restoration of SDS-dependent cell aggregation in strain $\mathrm{N}$ by complementation with DGCs strongly suggested that this process involved the second messenger c-di-GMP. To test this hypothesis we transformed strain PAO1 with the plasmid pBBR[CC3396] containing the 
gene for the known PDE CC3396 from Caulobacter crescentus (Christen et al., 2005). In strain PAO1 pBBR[CC3396] the roughness of colonies on SDScontaining agar plates (Fig. 1, B6) and the formation of macroscopic aggregates in SDS-containing liquid culture (Fig. 1, C6) were strongly reduced compared with the vector control strain PAO1 pBBR. Furthermore, strain PAO1 pBBR[CC3396] showed increased swarming motility (Fig. 1, D6) and a higher growth rate with SDS (Fig. 2A) than the suspended cells of the vector control (Fig. 1, D5; Fig. 2A). Pyocyanine production was only slightly decreased (Fig. 2B).

\section{SDS shock experiments with single and mixed cultures}

To compare the survival rates of the aggregating and non-aggregating $P$. aeruginosa strains, we submitted them to SDS-shock experiments in the presence and absence of CCCP. The individual strains were incubated with SDS alone before CCCP was added, thereby allowing those strains capable of aggregation to form aggregates. Colony-forming unit counts of strains PAO1 and N pUCP18[4929] decreased by about one order of magnitude after the exposure to CCCP compared with the solvent control (Fig. 3). In contrast, strains N and PAO1 pBBR[CC3396] suffered a dramatic decrease in cfu counts by more than four orders of magnitude compared with the solvent controls. These results clearly demonstrated that those strains capable of SDS-induced aggregation had a ca. 500-fold higher survival rate than those strains incapable of SDS-induced aggregation.

In the next step, we investigated whether the nonaggregating strains could be integrated into aggregates of strain PAO1 and, if so, whether they would benefit from this integration during exposure to SDS in the presence of CCCP. For this, we set up SDS shock experiments in which we mixed strain PAO1 with strains $\mathrm{N}, \mathrm{N}$ pUCP18[4929] and PAO1 pBBR[CC3396] at equal cell numbers prior to addition of SDS, as described under Experimental procedures. In all combinations, macroscopic cell aggregates were formed. Strain $\mathrm{N}$ accounted for $35.7 \%$ of the cfus released from aggregates formed with strain PAO1 (Fig. 4, A1). Thus, although strain $\mathrm{N}$ was incapable of SDS-induced aggregation it could be integrated into cell aggregates of the parental strain. This integration was confirmed by confocal laser scanning microscopy (CLSM) analysis of aggregates containing strains PAO1-Tn7-cfp and N-Tn7-yfp (Fig. 5A). Aggregates consisting mainly of strain PAO1 cells were interspersed with single cells and cell clusters of strain $\mathrm{N}$. When mixed cell suspensions with strains PAO1 and N were exposed to SDS in the presence of CCCP after strain $\mathrm{N}$ had been integrated into the aggregates, the percentage of strain $\mathrm{N}$ decreased to $14 \%$ (Fig. 4, A3). Considering the

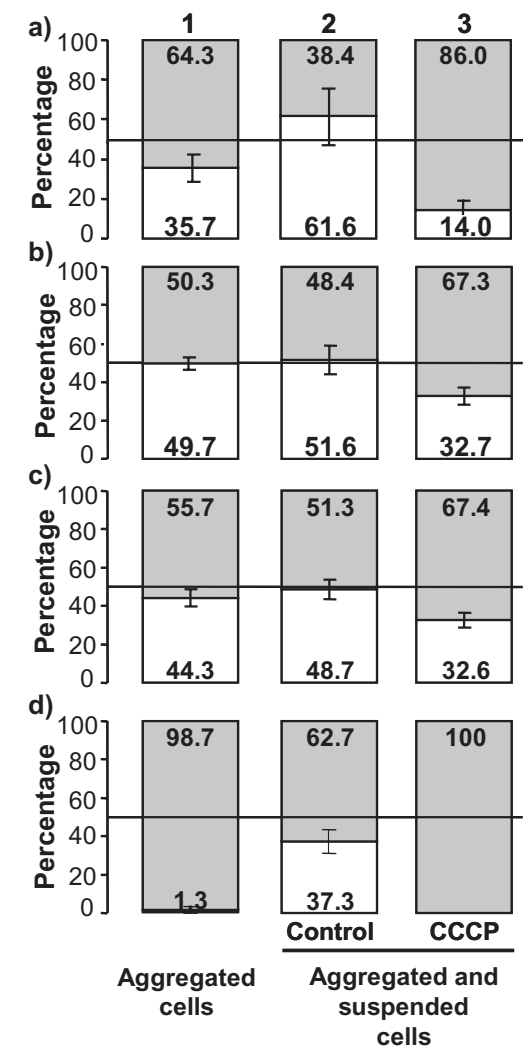

Fig. 4. SDS shock experiments with mixed cell suspensions of different $P$. aeruginosa strains.

Grey bars indicate percentages of total cfu counts of strains PAO1 pUCP18 (A, B, D) or PAO1 pBBR (C). White bars indicate percentages of total cfu counts of strains N pUCP18 (A), N pUCP18[4929] (B), PAO1 pBBR[CC3396] (C) and PAO1-D4 pUCP18 (D). Percentages were calculated after differentiating single colonies either by their colony morphology on SDS containing agar plates (A, C, D) or by the fluorescence of YFP- and CFP-tagged strains (B).

1. Percentages of individual strains in macroscopic cell aggregates formed after incubation of mixed cell suspensions with SDS for $45 \mathrm{~min}$.

2 and 3. Percentages of individual strains in whole cell suspensions (aggregated plus suspended cells) after incubation with SDS for $45 \mathrm{~min}$ and additional incubation with methanol as solvent control (2) or CCCP (3) for $60 \mathrm{~min}$.

Cell aggregates and whole cell suspensions were treated with DNase prior to cfu determination as described in Experimental procedures. Error bars indicate standard deviation $(n=3)$.

total cfu counts in these experiments (mean value of $4.33 \times 10^{7} \mathrm{cfu} \mathrm{ml}^{-1}$ ), this percentage equals $6 \times 10^{6} \mathrm{cfu} \mathrm{ml}^{-1}$. The cfus of strain $\mathrm{N}$ in the absence of strain PAO1 were $7.5 \times 10^{3}$ after exposure to SDS in the presence of CCCP (Fig. 3). Taking into account that twice as much cells of strain $\mathrm{N}$ were used in the single strain experiment, the survival rate of strain $\mathrm{N}$ was more than 1000 -fold higher in the presence of strain PAO1 than in cell suspensions of strain $\mathrm{N}$ alone. If strain $\mathrm{N}$ was complemented with pUCP18[4929], its percentage of cfus released from aggregates increased to about $50 \%$ (Fig. 4 , 

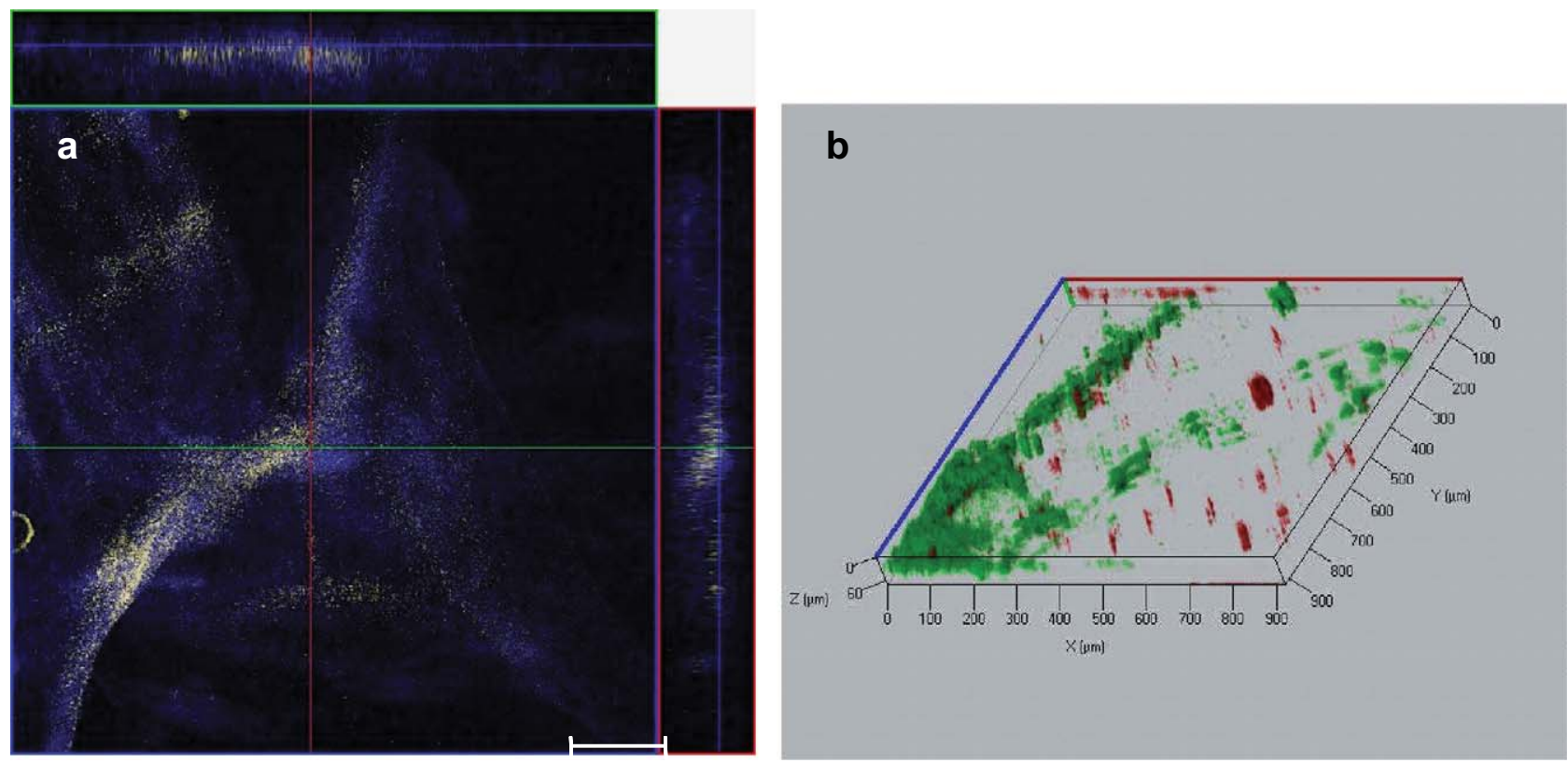

Fig. 5. Confocal laser scanning microscopy of cell aggregates formed by different $P$. aeruginosa strains.

A. Top-down view (central picture) and side views (flanking pictures) of an optical section through a cell aggregate formed by strain PAO1-Tn7-cfp (blue cells) and strain N-Tn7-yfp (yellow cells); the white bar $=146.2 \mu \mathrm{m}$.

B. Side-view projection of an aggregate formed by strain PAO1-Tn7-cfp stained with Syto9 (green) and TRITC-ConA (red).

B1). Complementation with pUCP18[4929] also increased the survival rate of strain $\mathrm{N}$ after addition of CCCP more than twofold (Fig. 4, B3). If strain PAO1 harboured pBBR[CC3396] its percentage of cfus released from aggregates was slightly reduced to $44.3 \%$ (Fig. 4, C1). This value was further decreased to $32.6 \%$ if the cells were exposed to SDS in the presence of CCCP (Fig. 4, C3).

\section{Co-cultivation of strains PAO1 and N}

To investigate whether strain $\mathrm{N}$ would also integrate into aggregates of strain PAO during growth with SDS, strains PAO1-Tn7-yfp and N-Tn7-cfp were coinoculated at a ratio of $5: 1$ and incubated with SDS as sole carbon and energy source. The final $\mathrm{OD}_{600}$ in these cultures was between the values for strain $\mathrm{N}$ and strain PAO1 (not shown). Freely suspended cells and cells released from aggregates were quantified by cfu counts and identified by their fluorescence. Strain N-Tn7-cfp accounted for $72 \%( \pm 2 \%)$ of the freely suspended cells and for $39 \%( \pm 5 \%)$ of cells released from aggregates. Thus, strain $\mathrm{N}$ was also integrated into aggregates of strain PAO1 during growth with SDS.

\section{Characterization of the transposon mutant strain PAO1-D4}

The discovery that smooth colony morphology on SDScontaining agar plates correlated with a non-aggregating phenotype during growth with SDS in liquid culture enabled us to conveniently screen for non-aggregating transposon mutants of strain PAO1. We created a mariner transposon mutant library of strain PAO1 and searched for smooth colonies on SDS-containing agar plates. From a first screening we isolated the transposon mutants PAO1-D1 and PAO1-D4. Sequence analysis revealed that the mariner transposons were inserted in the genes $p s / F$ and $p s / J$ respectively. These genes encode hypothetical proteins with homology to a putative glycosyltransferase $(p s / F)$ and polysaccharide polymerase $(p s / J)$. They are part of an operon ( $p s / A-O)$ which is responsible for exopolysaccharide biosynthesis and biofilm formation in P. aeruginosa (Friedman and Kolter, 2004; Jackson et al., 2004; Matsukawa and Greenberg, 2004; Ma et al., 2006). Both strains did not aggregate in liquid cultures with SDS. A role for ps/F in biofilm formation had already been described (Friedman and Kolter, 2004). We characterized the ps/J mutant strain PAO1-D4 further. Its physiological properties resembled those of strain $\mathrm{N}$, namely smooth colony morphology on SDS-containing agar plates (Fig. 1, A4), no aggregation and a higher growth rate with SDS in liquid culture (Fig. 1, B4; Fig. 2A), increased swarming motility (Fig. 1, D4), and strongly decreased pyocyanine production (Fig. 2B). As an important difference to strain $\mathrm{N}$, SDS-induced aggregation could not be restored in strain PAO1-D4 by transformation with pUCP18[4929].

In SDS shock experiments strain PAO1-D4 resembled strains $\mathrm{N}$ and PAO1 pBBR[CC3396] as treatment with 
SDS and CCCP caused a drop of cfu counts by more than four orders of magnitude compared with the solvent control (Fig. 3). In cell aggregates formed with strain PAO1 we found that strain PAO1-D4 accounted only for $1.3 \%$ of the cfus released from aggregates (Fig. 4, D1). If these cell suspensions were supplied with CCCP the cfus of strain PAO1-D4 were below the detection limit of $0.85 \%$ (Fig. 4, D3).

The impaired ability of strain PAO1-D4 to aggregate and to integrate into aggregates of the wild type suggested an important role of the ps/-dependent exopolysaccharides for cohesion of aggregates. The structure of this exopolysaccharide is not known but it was shown that it contains among other sugars mannose and glucose (Friedman and Kolter, 2004). By CLSM, we detected regions stainable with fluorescently labelled lectin TRITCConA which is specific for $\alpha$-glucose and $\alpha$-mannose (Fig. 5B). These regions were interspersed into regions stained with Syto9 as well as in areas that were not stained with this dye.

\section{Discussion}

The goal of our study was to define the physiological role of macroscopic cell aggregates formed by $P$. aeruginosa strain PAO1 during growth with the detergent SDS. Our investigation started with attempts to isolate mutants that were incapable of SDS-induced aggregation. We could isolate the non-aggregating spontaneous mutant strain $\mathrm{N}$ and two non-aggregating transposon mutants in which two genes of the $p s /$ operon ( $p s / J$ and $p s / F$ ) were inactivated. Strain $\mathrm{N}$ and the ps/ mutants were not impaired in growth with SDS but showed even higher growth rates than the parental strain PAO1. The successful selection for the loss-of-function mutant strain $\mathrm{N}$ in cultures growing with SDS and the growth advantage of the $\mathrm{ps} /$ mutants clearly signified SDS-induced cell aggregation of strain PAO1 a dispensable property under our cultivation conditions.

This conclusion raises the question why a part of the population of strain PAO1 did aggregate during growth with SDS. We have demonstrated that cells of $P$. aeruginosa in aggregates had a strongly increased survival rate when they were challenged with two toxic substances simultaneously, namely SDS plus CCCP. Under these conditions, the fast-growing, non-aggregating mutants of $P$. aeruginosa had a detrimental disadvantage. Encountering different toxic substances at the same time represents a realistic scenario that $P$. aeruginosa will face in hostile anthropogenic environments. Thus, our results force the hypothesis that cell aggregation is a pre-adaptive measure that is actively promoted by a subpopulation of $P$. aeruginosa to ensure survival under potentially worsening environmental conditions. The fact that $P$. aeruginosa cultures growing with SDS were divided into aggregating and nonaggregating subpopulations calls attention to the molecular basis of this phenotypic variation.

Cell aggregation in liquid cultures and formation of rough and structured colonies on agar plates during growth with SDS were reminiscent of two autoaggregative phenotypes frequently found among pseudomonads, the wrinkly spreader (Rainey and Rainey, 2003) and the small colony variants (Häußler, 2004). So far, both phenotypes have been described as constitutive phenotypic variations that regularly arise during growth in heterogeneous environments (Spiers et al., 2002; Goymer et al., 2006; Ude et al., 2006) and in biofilms, respectively (Deziel et al., 2001; Drenkard and Ausubel, 2002; Webb et al., 2004; Kirisits et al., 2005). Our results signify the autoaggregative phenotype as a facultative response that can be specifically induced by exposure to SDS. Mutational origins of autoaggregative phenotypes have been repeatedly found in genes involved in c-di-GMP metabolism (D'Argenio et al., 2002; Drenkard and Ausubel, 2002; Hickman et al., 2005; Goymer et al., 2006). We have obtained indirect but clear evidence of c-di-GMP being involved in SDSinduced aggregation. First, we could restore SDS-induced aggregation in strain $\mathrm{N}$ by complementation with three different DGCs, namely PA1107, PA1727 and PA4929. Diguanylate cyclase activity of PA1107 and PA1727 in $P$. aeruginosa has been demonstrated (Kulesekara et al., 2006). Second, SDS-induced aggregation could be reduced in strain PAO1 by expression of the known PDE CC3396 from C. crescentus (Christen et al., 2005).

Complementation with the genes PA1107 and PA4929 restored the autoaggregative phenotype in strain $\mathrm{N}$ in a SDS-dependent manner. However, as both genes were not mutated in strain $\mathrm{N}$ and their inactivation did not cause a phenotype in strain PAO1, a signalling pathway for SDS-induced aggregation cannot rely on these genes only. Rather, their complementing effect may rely on increasing the intracellular c-di-GMP concentration to a level required for SDS-induced aggregation. This possibility is supported by the effect of the PDE CC3396 because this heterologous enzyme should unspecifically reduce c-di-GMP levels in $P$. aeruginosa. However, despite various extraction methods all our attempts to detect c-di-GMP by high-performance liquid chromatography (HPLC) in SDS-grown cells of our strains failed so far (not shown). Several studies have provided evidence of c-di-GMP signalling being strictly regulated in space and time (Jenal and Malone, 2006) and acting in microcompartments (Weber et al., 2006). Considering that c-di-GMP synthesis is costly and growth with SDS is an energetical challenge, it would be feasible if c-di-GMP synthesis in SDS-grown cells of $P$. aeruginosa was strictly regulated, thereby rendering its intracellular pool below the detection limit. The fact that c-di-GMP biosynthesis in 
$P$. aeruginosa could be detected by HPLC analysis only upon overexpression of certain DGCs during growth in rich medium indicates that the levels of this second messenger are generally low in this organism (Kulesekara et al., 2006).

Recently, two operons involved in synthesis of exopolysaccharides, namely the psl (Jackson et al., 2004; Matsukawa and Greenberg, 2004) and the pel operons (Friedman and Kolter, 2004), have been identified as possible targets of c-di-GMP signalling in $P$. aeruginosa (Hickman et al., 2005). Our results with the nonaggregating $p s / F$ and $p s / J$ mutants clearly assigned an essential function for the $p s /$ gene cluster in SDS-induced aggregation. Staining with fluorescently labelled ConA lectins indicated that the mannose- and glucose-rich psdependent polysaccharide could be a part of the EPS in SDS-induced aggregates. It has been shown that ps/A was expressed in confined areas of biofilms (Overhage et al., 2005). A localized production of the ps/-dependent exopolysaccharide would be in agreement with the patchy distribution of the ConA signals within the aggregates. In conclusion, we have obtained evidence that SDS-induced aggregation involves a c-di-GMP signalling pathway that eventually activates synthesis of the psl-dependent exopolysaccharide. Our previous finding that aggregates contained a high proportion of damaged cells suggests that this signalling pathway could be triggered by so far unknown environmental or intracellular signals that indicate cell damage by SDS.

The complementing effect of PA1869 and pvcBCD cannot be explained at the present time. All four genes were not mutated in strain $\mathrm{N}$ and a non-polar deletion of PA1869 in strain PAO1 had no phenotype (J. Klebensberger and B. Philipp, unpublished).

We do currently not know which mutation is responsible for the stable non-aggregating phenotype of strain N. Our SDS shock experiments gave no indication that strain $\mathrm{N}$ was more resistant to SDS than the parental strain PAO1. A plausible cause for the higher growth rate of strain $\mathrm{N}$ could be increased mass transfer of SDS to suspended cells compared with aggregated cells. As the molar growth yields of both strains were equal they could invest equal amounts of energy into biomass production although they must have channelled part of their carbon source into different biosynthetic pathways because strain $\mathrm{N}$ did not form aggregates. However, as strain $\mathrm{N}$ complemented with DGCs was able to form cell aggregates indistinguishable from those of strain PAO1, it cannot be mutated in a gene required for EPS synthesis. The effective integration of strain $\mathrm{N}$ - in contrast to the $p s / J$ mutant strain PAO1-D4 - into aggregates of strain PAO1 suggested that strain $\mathrm{N}$ produced a basal level of adhesive EPS material. As the defect of strain $\mathrm{N}$ could be bypassed by expression of DGCs, we hypothesize that strain $\mathrm{N}$ is mutated in gene upstream of c-di-GMP signalling. The respective gene product could be involved in transducing SDS-induced stress to the postulated c-di-GMP signalling pathway.

We have shown that integration into aggregates of strain PAO1 conferred a substantial survival advantage for strain $\mathrm{N}$ upon exposure to SDS in the presence of CCCP. In this respect, cell aggregation could ensure genotypic and phenotypic diversity of $P$. aeruginosa populations which supports survival and growth in environments with fluctuating loads of multiple toxic chemicals, such as the aforementioned industrial wastewaters or clinical settings. Aggregating variants could increase population's survival chances under strongly adverse conditions while non-aggregating and fast-growing variants could increase the population's chances for rapid colonization of a new habitat when conditions improve. Pyocyanine production which accompanied cell aggregation in our experiments would be a means to inhibit competing microorganisms. To understand this survival strategy of $P$. aeruginosa in more detail, we are currently investigating the presumptive stress signals, the signal transduction pathways and the molecular targets involved in SDS-induced aggregation.

\section{Experimental procedures}

\section{Bacterial strains and growth media}

Bacterial strains and plasmids used in this study are listed in Table 1. Bacteria were cultivated in Luria-Bertani (LB) medium or in a modified M9 mineral medium supplied with $3.5 \mathrm{mM}$ SDS or $10 \mathrm{mM}$ Na-succinate as carbon and energy sources as described previously (Klebensberger et al., 2006). Colony morphologies for each $P$. aeruginosa strain are indicated in Table 1 as rough ( $\mathrm{RH}$ ) or smooth (SH). Plasmidharbouring Escherichia coli strains were selected and maintained on LB plates containing $100 \mathrm{\mu g} \mathrm{ml}^{-1}$ ampicillin (Fluka), $15 \mathrm{\mu g} \mathrm{ml}^{-1}$ gentamycin, $10 \mu \mathrm{g} \mathrm{ml}^{-1}$ tetracycline (Fluka) or $10 \mathrm{\mu g} \mathrm{ml}^{-1}$ kanamycin (Fluka). Plasmid-harbouring $P$. aeruginosa strains were selected on Pseudomonas isolation agar (PIA; Difco) containing $200 \mu \mathrm{g} \mathrm{ml}^{-1}$ carbenicillin (Sigma), $120 \mu \mathrm{g} \mathrm{ml}^{-1}$ gentamycin or $160 \mu \mathrm{g} \mathrm{ml}^{-1}$ tetracycline. In liquid M9 medium, the concentrations of carbenicillin and gentamycin were decreased to $50 \mathrm{\mu g} \mathrm{ml}^{-1}$ and $10 \mu \mathrm{g} \mathrm{ml}^{-1}$ respectively.

\section{Growth experiments and swarming assay}

Growth experiments with $P$. aeruginosa were performed as described previously (Klebensberger et al., 2006). For determination of molar growth yields $(Y)$ with SDS, cultures were incubated until onset of the stationary phase. Cells were harvested immediately by centrifugation at $15000 \mathrm{~g}$ for $10 \mathrm{~min}$ at $7^{\circ} \mathrm{C}$. To obtain the complete biomass, biofilms attached to the glass surface were scraped off and added to the fraction of suspended cells. The cells were washed once with $30 \mathrm{ml}$ of distilled water, resuspended in a small volume of 
Table 1. Strains and plasmids used in this study.

\begin{tabular}{|c|c|c|}
\hline Strains and plasmids & Relevant characteristics & Source or reference \\
\hline \multicolumn{3}{|l|}{$P$. aeruginosa } \\
\hline PAO1 & Wild type of strain PAO1 $(\mathrm{RH})$ & Holloway collection \\
\hline $\mathrm{N}$ & Spontaneous mutant of strain PAO1 (SH) & This study \\
\hline PAO1-Tn7-yfp & PAO1 with Tn7 chromosomal insertion of $y f p(\mathrm{RH})$ & This study \\
\hline N-Tn7-cfp & $\mathrm{N}$ with $\mathrm{Tn} 7$ chromosomal insertion of $c f p(\mathrm{SH})$ & This study \\
\hline PAO1-D1 & $\begin{array}{l}\text { Mariner transposon mutant of strain PAO1, insertion at position } \\
596 \text { of gene ps/F (1178 bp) (SH) }\end{array}$ & This study \\
\hline PAO1-D4 & $\begin{array}{l}\text { Mariner transposon mutant of strain PAO1, insertion at position } \\
1118 \text { of gene pslJ (1437 bp) }(\mathrm{SH})\end{array}$ & This study \\
\hline PAO1-KO[1107] & PAO1, PA1107::pKO[1107] (RH) & This study \\
\hline PAO1-KO[1727] & PAO1, PA1727::pKO[1727] (RH) & This study \\
\hline PAO1-KO[4929] & PAO1, PA4929::pKO[4929] (RH) & This study \\
\hline \multicolumn{3}{|l|}{ E. coli } \\
\hline JM109 & 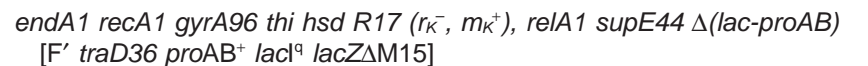 & Promega \\
\hline SM10::入pir & thi1 thr1 leuB6 supE44 tonA21 lacY1 recA::RP4-2-Tc::Mu Km $\lambda$ pir & Miller and Mekalanos (1988) \\
\hline HB101 & $\begin{array}{l}\text { thi-1 hsd } \mathrm{S} 20\left(\mathrm{r}_{\mathrm{B}}^{-}, \mathrm{m}_{\mathrm{B}}^{-}\right) \text {supE44 recA13 ara-14 leuB6 proA2 lacY1 } \\
\text { rpsL20 (str') xyl-5 mtl-1 galK2 }\end{array}$ & Promega \\
\hline S17-1 & thi pro hsdR hsdM+ recA RP4-2-Tc::Mu-Km::Tn7 & Simon et al. (1983) \\
\hline \multicolumn{3}{|l|}{ Plasmids } \\
\hline pUCP18 & Escherichia-Pseudomonas shuttle vector (Ap') & West et al. (1994) \\
\hline pKnockout-G & Suicide vector used for gene inactivation $\left(\mathrm{Ap}^{r}, \mathrm{Gm}^{\mathrm{r}}\right)$ & Windgassen et al. (2000) \\
\hline PALMAR3 & $\begin{array}{l}\text { Plasmid harbouring a mariner transposon used for transposon } \\
\text { mutagenesis (Tet') }\end{array}$ & Jenal lab \\
\hline $\begin{array}{l}\text { pBK-miniTn7(gm) } \\
\text { PA1/04/03-eyfp-a }\end{array}$ & Plasmid for chromosomal integration of $y f p\left(\mathrm{Ap}^{r}, \mathrm{Gm}^{r}, \mathrm{Cm}^{r}\right)$ & Klausen et al. (2003) \\
\hline $\begin{array}{l}\text { pBK-miniTn7(gm) } \\
\text { PA1/04/03-ecfp-a }\end{array}$ & Plasmid for chromosomal integration of $c f p\left(\mathrm{Ap}^{r}, \mathrm{Gm}^{r}, \mathrm{Cm}^{r}\right)$ & Klausen et al. (2003) \\
\hline pBBR1MSC-5 & Broad-host-range cloning vector $\left(\mathrm{Gm}^{r}\right)$ & Kovach et al. (1995) \\
\hline pBBR[CC3396] & pBBR1MSC- 5 containing gene CC3396 from C. crescentus & Jenal lab \\
\hline KN6B and KN7C & Complementing plasmids harbouring the genes $p v c B C D$ (c. $3900 \mathrm{bp})$ & This study \\
\hline KN2C and NNG1 & $\begin{array}{l}\text { Complementing plasmids harbouring the single gene PA1869 } \\
\text { (c. } 1200 \mathrm{bp})\end{array}$ & This study \\
\hline pUCP18[1107] & $\begin{array}{l}\text { pUCP18 harbouring a Smal fragment (2008 bp) encoding the single } \\
\text { gene PA1107 }\end{array}$ & This study \\
\hline pUCP18[1727] & $\begin{array}{l}\text { pUCP18 harbouring a EcoRI-HindIII fragment (2476 bp) encoding } \\
\text { the single gene PA1727 }\end{array}$ & This study \\
\hline pUCP18[4929] & $\begin{array}{l}\text { pUCP18 harbouring a Sall fragment (2426 bp) encoding the single } \\
\text { gene PA4929 }\end{array}$ & This study \\
\hline pKO[1107] & pKnockout-G harbouring an internal EcoRI fragment (883 bp) of PA1107 & This study \\
\hline pKO[1727] & pKnockout-G harbouring an internal Hincll fragment (702 bp) of PA1727 & This study \\
\hline pKO[4929] & $\begin{array}{l}\text { pKnockout-G harbouring an internal BamHI-Pstl fragment (908 bp) } \\
\text { of PA4929 }\end{array}$ & This study \\
\hline pUX-BF13 & Plasmid providing the $T n 7$ transposase genes $\left(A p^{r}\right)$ & Bao et al. (1991) \\
\hline pRK 600 & ori ColE1 RK2-Mob ${ }^{+}$RK2-Tra ${ }^{+}\left(\mathrm{Cm}^{r}\right)$ & Kessler et al. (1992) \\
\hline
\end{tabular}

$(\mathrm{RH})$ indicates rough colony morphology on SDS-containing agar. $(\mathrm{SH})$ indicates smooth colony morphology on SDS-containing agar.

distilled water, transferred to weight-constant test tubes, and centrifuged at $2000 \mathrm{~g}$ for $10 \mathrm{~min}$ at $7^{\circ} \mathrm{C}$. Supernatants were decanted and cell pellets were completely dried at $70^{\circ} \mathrm{C}$. After cooling the tubes in a desiccator, the dry weights were determined. SDS concentrations at the beginning and at the end of growth were determined as described previously (Klebensberger et al., 2006).

Swarming motility was determined as described previously (D'Argenio et al., 2002).

\section{Gene library construction and complementation of mutants}

Genomic DNA of strain PAO1 was purified (Puregene DNA Isolation Kit, Gentra) and partially digested with Sau3AI. DNA fragments between $1 \mathrm{~kb}$ and $8 \mathrm{~kb}$ were extracted and purified (E.Z.N.A Gel Extraction Kit, Peqlab) from agarose gels and ligated into the BamHI restriction site of pUCP18 (West et al., 1994). Competent E. coli JM109 cells (Promega) were transformed with these plasmids and submitted to ampicillin selection and blue-white screening. Six thousand positive clones were transferred into 96 -well plates by pooling five clones per well in $200 \mu \mathrm{l}$ of LB with ampicillin and grown with shaking at 200 r.p.m. for $24 \mathrm{~h}$ at $37^{\circ} \mathrm{C}$. All pools of transformants were combined at equal volumes, washed twice in LB medium and frozen as glycerol stocks $(40 \% \mathrm{v} / \mathrm{v})$ in liquid nitrogen. The plasmids from this gene library were extracted (peqGold Plasmid Miniprep Kit I, Peqlab) and transformed into $P$. aeruginosa strain N (Irani and Rowe, 1997). Transformants were screened on M9 agar plates containing $0.15 \%$ SDS and $125 \mu \mathrm{g} \mathrm{ml}^{-1}$ carbenicillin. Clones with rough colony morphol- 


\begin{tabular}{|c|c|}
\hline Primers & Sequence \\
\hline \multicolumn{2}{|c|}{ Chromosomal insertion analysis } \\
\hline pKO-G & 5'-GCGCGTTGGCCGATTCATTA-3' \\
\hline PA1107-Check-R & 5'-CTGGTCGGCGGCGCTGTAGAG-3' \\
\hline PA1727-Check-R & 5'-CCGGCAGGCGTTTGAGATACAG-3' \\
\hline PA4929-Check-R & 5'-CTGGTCGGCGGCCTTGTAGAGTTT-3' \\
\hline Tn7-GImS & 5'-AATCTGGCCCAAGTCGGTGAC-3' \\
\hline Tn7R109 & 5'-CAGCATAACTGGACTGATTTCAG-3' \\
\hline \multicolumn{2}{|c|}{ Transposon insertion analysis } \\
\hline Marseq- $\mathrm{F}$ & 5'-TGAATGCGCAAACCAACCCTTGGC-3' \\
\hline Marseq- $\mathrm{R}$ & 5'-GGAAACAGCTATGACCATGATTACGCC-3' \\
\hline \multicolumn{2}{|l|}{ Sequence analysis } \\
\hline PA1107-F & 5'-GACGCGCCGGAGCCCTGTTCG-3' \\
\hline PA1107-R & 5'-GAGCGCCACGGACCATCTTA-3' \\
\hline PA 1727-F & 5'-GGGAATTCCATGAGACGCACCTCCTGT-3' \\
\hline PA $1727-R$ & 5'-GCGATGGGCGAATCTGAAGCTTCTGAC-3' \\
\hline PA4929-F & 5'-GAAGGGCGCCGGACCGAAACACTC-3' \\
\hline PA4929-R & 5'-TGCGGCCGGGAATCATGCTCTACG-3' \\
\hline PA 1869-F & 5'-CGGGCCCTGGCGGAACTG-3' \\
\hline PA 1869-R & 5'-GCGGCGGCGGGCAAAAA-3' \\
\hline pvc-F & 5'-CTCGCCGCGGTCAGCCAGTG-3' \\
\hline pvc-R & 5'-CGTTTCCGCGGCGTTCATCC-3' \\
\hline
\end{tabular}

ogy were further tested for SDS-induced aggregation in $3 \mathrm{ml}$ of $\mathrm{M} 9$ medium containing $0.1 \%$ SDS in small Petridishes $(3.5 \mathrm{~cm}$ in diameter; Nunc) on a rotary shaker at 120 r.p.m. (Orbital Incubator S150, Stuart Scientific) for $18 \mathrm{~h}$ at $30^{\circ} \mathrm{C}$. Plasmids that restored aggregation of strain $\mathrm{N}$ in liquid media were isolated, the chromosomal fragments were sequenced and identified by comparison with the Pseudomonas Genome Project database (http://v2.pseudomonas.com/).

\section{Construction of plasmids and insertional mutants}

To construct plasmids pUCP18[1107], pUCP[1727] and pUCP18[4929], the genes PA1107, PA1727 and PA4929 were excised as fragments from the inserts of complementing plasmids as Smal, EcoRI-HindIII and Sall fragments, respectively, and cloned into pUCP18 digested with the respective enzymes. To construct the plasmids pKO[1107], pKO[1727] and pKO[4929], internal fragments (indicated in Table 1) of PA1107, PA1727 and PA4929 were cloned into the respective restriction sites of the suicide vector pKnockout-G (Windgassen et al., 2000). The resulting plasmids were transferred in strain PAO1 by bi-parental mating (see below) with E. coli strain S17-1 as donor. Correct chromosomal insertion of the vectors was confirmed by PCR with appropriate primers (Table 2).

\section{Transposon mutagenesis}

For random transposon mutagenesis of strain PAO1, the vector PALMAR3 carrying a mariner transposon (Lampe et al., 1999) with a tetracycline resistance gene was used (kindly provided by Urs Jenal). For bi-parental matings, E. coli S17-1 harbouring pALMAR3 (donor) was grown in LB medium with shaking at 150 r.p.m. at $37^{\circ} \mathrm{C}$, while strain PAO1 (recipient) was grown in LB medium with shaking at 50 r.p.m. at $42^{\circ} \mathrm{C}$. After incubation overnight, $5 \times 10^{8}$ cells of the donor and $1 \times 10^{9}$ cells of the recipient were harvested by
Table 2. Primers used in this study.

Table 2. Primers used in this study. centrifugation at 10000 r.p.m. for $1.5 \mathrm{~min}$ (5415 D; Eppendorf), washed twice in $2 \mathrm{ml}$ of prewarmed LB medium, and finally resuspended in $50 \mu$ of LB medium. Donor and recipient were carefully mixed by pipetting and spread onto sterile membrane filters (OE66 $0.2 \mu \mathrm{m} 25$ mm diameter; Schleicher and Schuell) that were placed on prewarmed LB agar plates. After incubation for $6 \mathrm{~h}$ at $37^{\circ} \mathrm{C}$, the filters were transferred to a $50 \mathrm{ml}$ plastic tube (Greiner) containing $2 \mathrm{ml}$ of $\mathrm{NaCl}(0.9 \%)$. After vortexing, aliquots of the cell suspensions were spread on PIA agar plates containing $160 \mu \mathrm{g} \mathrm{ml}^{-1}$ tetracycline to select for transposon mutants of strain PAO1. After incubation for $48 \mathrm{~h}$ at $37^{\circ} \mathrm{C}$, all colonies $(-20000)$ were scraped off, transferred into a plastic tube containing $25 \mathrm{ml}$ of $\mathrm{NaCl}$ $(0.9 \%, \mathrm{w} / \mathrm{v})$, washed twice and finally resuspended in $4 \mathrm{ml}$ of LB medium.

Transposon mutants with smooth colony morphology on M9 agar plates containing $0.15 \%$ SDS and $80 \mu \mathrm{g} \mathrm{ml}^{-1}$ tetracycline were further screened for SDS-induced aggregation in liquid culture. In non-aggregating mutants, the exact position of the transposon insertion was identified by inverse PCR with primers indicated in Table 2 in cooperation with Trenzyme $\mathrm{GmbH}$ (Konstanz). Transposon insertion sites were identified by comparison with the Pseudomonas Genome Project database. Strains PAO1-Tn7-yfp and N-Tn7-cfp were constructed through site-directed transposon insertion into the chromosome via four-parental mating as described previously (Klausen et al., 2003).

\section{SDS shock experiments}

SDS shock experiments with cell suspensions of single cultures of different $P$. aeruginosa strains were performed as described previously (Klebensberger et al., 2006). In SDS shock experiments with mixed cell suspensions of different $P$. aeruginosa strains, $500 \mu \mathrm{l}$ from cell suspensions $\left(\mathrm{OD}_{600}=1.5\right)$ of two different strains were combined in one well of a 24-well microtitre plate (Nunclon Surface, Nunc), 
supplied with SDS $(3.5 \mathrm{mM})$ and incubated on a rotary shaker at 200 r.p.m and $30^{\circ} \mathrm{C}$ for $45 \mathrm{~min}$. After macroscopic aggregates had formed, they were separated from the suspended cells. For this, aggregates were transferred into $30 \mathrm{ml}$ of DNase buffer $(50 \mathrm{mM}$ Tris- $\mathrm{HCl}$ with $10 \mathrm{mM} \mathrm{MgCl} 2$ at $\mathrm{pH}$ 7.2) with a pipette, harvested by centrifugation at $80 \mathrm{~g}$ for $5 \mathrm{~min}$, washed twice and finally resuspended in $3 \mathrm{ml}$ of DNase buffer. Aggregates were disintegrated by treatment with DNase I (Type II, stock solution in water, Sigma) for $30 \mathrm{~min}$ at $37^{\circ} \mathrm{C}$. Cells released from aggregates and cells that had remained in suspension during SDS shock were quantified by cfu counts as described previously (Klebensberger et al., 2006). As controls, single cultures of the individual strains were submitted to the same procedure in parallel.

To determine the survival rates of strains in single or mixed culture after exposure to SDS plus CCCP (Sigma), SDS shock experiments were set up as described above. After $45 \mathrm{~min}$, cell suspensions were supplied with CCCP (1 mM) and incubated for additional 60 min with shaking at 75 r.p.m. Then, the complete cell suspensions (suspended cells plus aggregates) were transferred into $30 \mathrm{ml}$ of DNase buffer and harvested by centrifugation at $10000 \mathrm{~g}$ for $8 \mathrm{~min}$ at room temperature. After washing, the cells were resuspended in DNase buffer in a final volume of $3 \mathrm{ml}$ and treated with DNase I for $30 \mathrm{~min}$ at $37^{\circ} \mathrm{C}$. Colony-forming unit counts were determined as described above. Cell suspensions with methanol were used as controls.

Single colonies of the individual strains from experiments with mixed cultures were identified by their colony morphology or by their fluorescence. To identify strains by their colony morphology, $50 \mu \mathrm{l}$ aliquots of appropriately diluted cell suspensions were spread onto agar plates containing M9 medium containing $0.15 \%$ SDS. After incubation for 2 days at $37^{\circ} \mathrm{C}$, rough and smooth colonies could be unambiguously differentiated and counted. To identify YFP- and CFP-tagged strains, $50 \mu$ l aliquots of appropriately diluted cell suspensions were spread onto LB agar plates containing the respective antibiotics. At least 60 single colonies were picked and grown in $200 \mu \mathrm{l}$ of LB medium in 96-well plates with shaking at 200 r.p.m. at $37^{\circ} \mathrm{C}$. After $14 \mathrm{~h}$ of incubation, the $\mathrm{OD}_{595}$ and the relative fluorescence (RFU) at $535 \mathrm{~nm}$ (excitation at $485 \mathrm{~nm}$ ) were measured with a microtitreplate reader (GENIOS, Tecan). The strains could be unambiguously differentiated by their ratio of RFU/OD ${ }_{595}$ because YFP-tagged strains showed a significantly higher $\mathrm{RFU} / \mathrm{OD}_{595}$ than CFP-tagged strains. The RFU/OD 595 ratio of the latter was in the same range as that of untagged strains.

All SDS shock experiments were performed in triplicates and reproduced in at least two independent runs.

\section{Other analytical methods}

Determination of sulfatase activity and protein concentration in cell-free extracts were performed as described previously (Klebensberger et al., 2006).

For pyocyanine determination, aliquots $(5 \mathrm{ml})$ of supernatants from SDS-grown cultures from early stationary phase were extracted with chloroform $(3 \mathrm{ml})$ in a plastic tube (Sarstaedt). After centrifugation at $2000 \mathrm{~g}$ for $2 \mathrm{~min}, 2 \mathrm{ml}$ of the chloroform phase was transferred to a new tube and subsequently mixed with $1 \mathrm{ml}$ of $0.2 \mathrm{M} \mathrm{HCl}$. Pyocyanine was determined by measuring the absorbance of the aqueous phase at $520 \mathrm{~nm}\left(\mathrm{~A}_{520}\right)$.

For nucleotide extraction, cell suspensions $(9 \mathrm{ml}$, $\left.\mathrm{OD}_{600}=1.5\right)$ were shocked with SDS as described above. After $1 \mathrm{~h}$, cells were supplied with $10 \mathrm{ml}$ of ice cold DNase buffer, centrifuged at $15000 \mathrm{~g}$ for $1 \mathrm{~min}$ at $4^{\circ} \mathrm{C}$, and immediately extracted either with $1 \mathrm{M}$ formic acid or by boiling in $65 \%$ ethanol $(\mathrm{v} / \mathrm{v})$. Extracts were separated from cell debris by centrifugation, lyophilized, and finally dissolved $200 \mu \mathrm{l}$ in distilled water. Extracts were analysed with a reversed-phase HPLC system (Philipp et al., 2006) using 100 mM sodiumphosphate buffer pH 5.8 (eluent $\mathrm{A}$ ) and acetonitrile (eluent B) at a flow rate of $0.7 \mathrm{ml} \mathrm{min}^{-1}$ at room temperature. For separation of nucleotides a gradient was applied starting with $5 \%$ $\mathrm{B}$ for $10 \mathrm{~min}$, then rising to $70 \% \mathrm{~B}$ within $10 \mathrm{~min}$ and returning to $5 \% \mathrm{~B}$ within $1 \mathrm{~min}$ followed by 7 min equilibration. A standard of c-di-GMP (BIOLOG Life Science) eluted after about $15 \mathrm{~min}$.

\section{CLSM and macroscopic images}

Macroscopic aggregates of $P$. aeruginosa cells labelled with CFP and YFP were placed on glass slides and fixed by embedding them in polyacrylamide (13\%). Microscopic investigation was performed either directly or after staining of the bacterial aggregates with the DNA binding fluorochrome SYTO 9 (Molecular Probes) and the lectin concanavalin A labelled with the fluorescent dye tetramethyl rhodamine isothiocyanate (TRITC-ConA, Sigma). Samples were stained by layering a solution containing TRITC-ConA $\left(10 \mu \mathrm{g} \mathrm{ml}^{-1}\right)$ and SYTO $9\left(1.5 \mu \mathrm{ml}^{-1}\right)$ in deionized water on top of the aggregates, incubating them statically for $20 \mathrm{~min}$ in the dark and washing them twice in deionized water. Microscopic examination was performed with a LSM 510 confocal laser scanning microscope (Zeiss, Germany), consisting of a laser scanning module that was mounted on an Axiovert $100 \mathrm{M} \mathrm{BP}$ inverted microscope (Zeiss) equipped with the following objectives (Zeiss): Plan-Neofluar 10×/0.30, LD-Achroplan $40 \times / 0.60$ Korr and LD-Achroplan 63×/0.75 Korr Ph2. An argon laser and a helium-neon laser were applied for the analysis of the samples. Images of CFP-labelled cells were recorded at an excitation wavelength of $458 \mathrm{~nm}$ and an emission wavelength of $475-515 \mathrm{~nm}$; images of YFP-labelled cells were recorded at an excitation wavelength of $488 \mathrm{~nm}$ and emission wavelength > $515 \mathrm{~nm}$, using a LP $505 \mathrm{~nm}$ longpass detection filter. Aggregates stained with SYTO 9 and TRITC-ConA were visualized at an excitation wavelength of $488 \mathrm{~nm}$ and an emission wavelength range of $505 \mathrm{~nm}-550 \mathrm{~nm}$ provided by a BP 505-550 band-pass filter (SYTO 9) and at an excitation wavelength of $543 \mathrm{~nm}$ and an emission wavelength $>570 \mathrm{~nm}$ using an LP 560 long-pass filter (TRITC-ConA). Image recording of optical thin sections was performed with the LSM software (version 3.2 SP2, Zeiss). Image analysis including data processing and threedimensional reconstruction was performed using the AxioVision software version 3.1 (Zeiss). Macroscopic images of colonies, SDS-induced aggregation and swarming plates were taken with a Canon Powershot G6 camera. Images were processed with Paint Shop Pro 4. 


\section{Acknowledgements}

The authors like to thank Urs Jenal, Jakob Malone and Alexander Boehm from the Biozentrum Basel for the gift of pALMAR3 and pBBR[CC3396] as well as for helpful discussions. Technical assistance from Antje Karst, Anja Holtz and Oliver Popp and continuous support from Bernhard Schink is acknowledged. This work was funded by a grant from the Deutsche Forschungsgemeinschaft to BP (PH71/2-1).

\section{References}

Allesen-Holm, M., Barken, K.B., Yang, L., Klausen, M., Webb, J.S., Kjelleberg, S., et al. (2006) A characterization of DNA release in Pseudomonas aeruginosa cultures and biofilms. Mol Microbiol 59: 1114-1128.

Bao, Y., Lies, D.P., Fu, H., and Roberts, G.P. (1991) An improved Tn7-based system for the single-copy insertion of cloned genes into chromosomes of gram-negative bacteria. Gene 109: 167-168.

Chan, C., Paul, R., Samoray, D., Amiot, N.C., Giese, B., Jenal, U., and Schirmer, T. (2004) Structural basis of activity and allosteric control of diguanylate cyclase. Proc Natl Acad Sci USA 101: 17084-17089.

Christen, M., Christen, B., Folcher, M., Schauerte, A., and Jenal, U. (2005) Identification and characterization of a cyclic di-GMP-specific phosphodiesterase and its allosteric control by GTP. J Biol Chem 280: 30829-30837.

Clarke, P.H. (1982) The metabolic versatility of pseudomonads. Antonie Van Leeuwenhoek 48: 105-130.

D'Argenio, D.A., Calfee, M.W., Rainey, P.B., and Pesci, E.C. (2002) Autolysis and autoaggregation in Pseudomonas aeruginosa colony morphology mutants. J Bacteriol 184: 6481-6489.

Deziel, E., Comeau, Y., and Villemur, R. (2001) Initiation of biofilm formation by Pseudomonas aeruginosa 57RP correlates with emergence of hyperpiliated and highly adherent phenotypic variants deficient in swimming, swarming, and twitching motilities. J Bacteriol 183: 1195-1204.

Drenkard, E. (2003) Antimicrobial resistance of Pseudomonas aeruginosa biofilms. Microbes Infect 5: 1213-1219.

Drenkard, E., and Ausubel, F.M. (2002) Pseudomonas biofilm formation and antibiotic resistance are linked to phenotypic variation. Nature 416: 740-743.

Emori, T.G., and Gaynes, R.P. (1993) An overview of nosocomial infections, including the role of the microbiology laboratory. Clin Microbiol Rev 6: 428-442.

Friedman, L., and Kolter, R. (2004) Two genetic loci produce distinct carbohydrate-rich structural components of the Pseudomonas aeruginosa biofilm matrix. J Bacteriol 186: 4457-4465.

Fux, C.A., Costerton, J.W., Stewart, P.S., and Stoodley, P. (2005) Survival strategies of infectious biofilms. Trends Microbiol 13: 34-40.

Gilbert, P., Maira-Litran, T., McBain, A.J., Rickard, A.H., and Whyte, F.W. (2002) The physiology and collective recalcitrance of microbial biofilm communities. Adv Microb Physiol 46: 202-256.

Goymer, P., Kahn, S.G., Malone, J.G., Gehrig, S.M., Spiers, A.J., and Rainey, P.B. (2006) Adaptive divergence in experimental populations of Pseudomonas fluorescens. II. Role of the GGDEF regulator WspR in evolution and development of the wrinkly spreader phenotype. Genetics 173: 515-526.

Hagelueken, G., Adams, T.M., Wiehlmann, L., Widow, U., Kolmar, H., Tümmler, B., et al. (2006) The crystal structure of SdsA1, an alkylsulfatase from Pseudomonas aeruginosa, defines a third class of sulfatases. Proc Natl Acad Sci USA 103: 7631-7636.

Häußler, S. (2004) Biofilm formation by the small colony variant phenotype of Pseudomonas aeruginosa. Environ Microbiol 6: 546-551.

Helenius, A., and Simons, K. (1975) Solubilization of membranes by detergents. Biochim Biophys Acta 415: 29-79.

Hickman, J.W., Tifrea, D.F., and Harwood, C.S. (2005) A chemosensory system that regulates biofilm formation through modulation of cyclic diguanylate levels. Proc Natl Acad Sci USA 102: 14422-14427.

Hoffman, L.R., D’Argenio, D.A., MacCoss, M.J., Zhang, Z., Jones, R.A., and Miller, S.I. (2005) Aminoglycoside antibiotics induce bacterial biofilm formation. Nature 436: 1171-1175.

Irani, V.R., and Rowe, J.J. (1997) Enhancement of transformation in Pseudomonas aeruginosa PAO1 by $\mathrm{Mg}^{2+}$ and heat. Biotechniques 22: 54-56.

Jackson, K.D., Starkey, M., Kremer, S., Parsek, M.R., and Wozniak, D.J. (2004) Identification of psl, a locus encoding a potential exopolysaccharide that is essential for Pseudomonas aeruginosa PAO1 biofilm formation. $J$ Bacteriol 186: 4466-4475.

Jenal, U., and Malone, J. (2006) Mechanisms of cyclic-diGMP signaling in bacteria. Annu Rev Genet 40: 385-407.

Kessler, B., de Lorenzo, V., and Timmis, K.N. (1992) A general system to integrate lacZ fusions into the chromosomes of gram-negative eubacteria: regulation of the Pm promoter of the TOL plasmid studied with all controlling elements in monocopy. Mol Gen Genet 233: 293-301.

Kirisits, M.J., Prost, L., Starkey, M., and Parsek, M.R. (2005) Characterization of colony morphology variants isolated from Pseudomonas aeruginosa biofilms. Appl Environ Microbiol 71: 4809-4821.

Klausen, M., Heydorn, A., Ragas, P., Lambertsen, L., AaesJorgensen, A., Molin, S., and Tolker-Nielsen, T. (2003) Biofilm formation by Pseudomonas aeruginosa wild type, flagella and type IV pili mutants. Mol Microbiol 48: 15111524.

Klebensberger, J., Rui, O., Fritz, E., Schink, B., and Philipp, B. (2006) Cell aggregation of Pseudomonas aeruginosa strain PAO1 as an energy-dependent stress response during growth with sodium dodecyl sulfate. Arch Microbiol 185: 417-427.

Kovach, M.E., Elzer, P.H., Hill, D.S., Robertson, G.T., Farris, M.A., Roop II, R.M., and Peterson, K.M. (1995) Four new derivatives of the broad-host-range cloning vector pBBR1MLS, carrying different antibiotic-resistance cassettes. Gene 166: 175-176.

Kulesekara, H., Lee, V., Brencic, A., Liberati, N., Urbach, J., Miyata, S., et al. (2006) Analysis of Pseudomonas aeruginosa diguanylate cyclases and phosphodiesterases reveals a role for bis-(3'-5')-cyclic-GMP in virulence. Proc Natl Acad Sci USA 103: 2839-2844. 
Lampe, D.J., Akerley, B.J., Rubin, E.J., Mekalanos, J.J., and Robertson, H.M. (1999) Hyperactive transposase mutants of the Himar1 mariner transposon. Proc Natl Acad Sci USA 96: 11428-11433.

Lewis, K. (2001) Riddle of biofilm resistance. Antimicrob Agents Chemother 45: 999-1007.

Linker, A., and Jones, R.S. (1964) A polysaccharide resembling alginic acid from a Pseudomonas micro-organism. Nature 204: 187-188.

Ma, L., Jackson, K.D., Landry, R.M., Parsek, M.R., and Wozniak, D.J. (2006) Analysis of Pseudomonas aeruginosa conditional psl variants reveals roles for the psl polysaccharide in adhesion and maintaining biofilm structure post-attachment. J Bacteriol 188: 82138221.

Matsukawa, M., and Greenberg, E.P. (2004) Putative exopolysaccharide synthesis genes influence Pseudomonas aeruginosa biofilm development. J Bacteriol 186: 4449-4456.

Miller, V.L., and Mekalanos, J.J. (1988) A novel suicide vector and its use in construction of insertiion mutations: osmoregulation of outer membcane proteins and virulence determinants in Vibrio cholerae requires toxR. J. Bacteriol 170: 2575-2583.

Muscarella, L.F. (2004) Contribution of tap water and environmental surfaces to nosocomial transmission of antibiotic-resistant Pseudomonas aeruginosa. Infect Control Hosp Epidemiol 25: 342-345.

Overhage, J., Schemionek, M., Webb, J.S., and Rehm, B.H. (2005) Expression of the ps/ operon in Pseudomonas aeruginosa PAO1 biofilms: PsIA performs an essential function in biofilm formation. Appl Environ Microbiol 71: 4407-4413.

Philipp, B., Erdbrink, H., Suter, M., and Schink, B. (2006) Degradation of and sensitivity to cholate in Pseudomonas sp. strain Chol1. Arch Microbiol 185: 192-201.

Poole, K. (2004) Efflux-mediated multiresistance in Gramnegative bacteria. Clin Microbiol Infect 10: 12-26.

Rainey, P.B., and Rainey, K. (2003) Evolution of cooperation and conflict in experimental bacterial populations. Nature 425: 72-74.

Rajagopal, S., Sudarsan, N., and Nickerson, K.W. (2002) Sodium dodecyl sulfate hypersensitivity of $c / p P$ and $c / p B$ mutants of Escherichia coli. Appl Environ Microbiol 68: 4117-4121.

Rodrigue, A., Quentin, Y., Lazdunski, A., Mejean, V., and Foglino, M. (2000) Two-component systems in Pseudomonas aeruginosa: why so many? Trends Microbiol 8: 498504.

Römling, U., Gomelsky, M., and Galperin, M.Y. (2005) C-diGMP: the dawning of a novel bacterial signalling system. Mol Microbiol 57: 629-639.
Ross, P., Aloni, Y., Weinhouse, H., Michaeli, D., WeinbergerOhana, P., Mayer, R., and Benziman, M. (1986) Control of cellulose synthesis Acetobacter xylinum. A unique guanyl oligonucleotide is the immediate activator of the cellulose synthase. Carbohydr Res 149: 101.

Ryan, R.P., Fouhy, Y., Lucey, J.F., Crossman, L.C., Spiro, S., He, Y.W., et al. (2006) Cell-cell signaling in Xanthomonas campestris involves an HD-GYP domain protein that functions in cyclic di-GMP turnover. Proc Natl Acad Sci USA 103: 6712-6717.

Ryjenkov, D.A., Tarutina, M., Moskvin, O.V., and Gomelsky, M. (2005) Cyclic diguanylate is a ubiquitous signaling molecule in bacteria: insights into biochemistry of the GGDEF protein domain. J Bacteriol 187: 1792-1798.

Simon, R., Priefer, U., and Pühler, A. (1983) A broad host range mobilization system for in vivo genetic engineering: transposon mutagenesis in gram negative bacteria. Biotechnology 1: 784-791.

Spiers, A.J., Kahn, S.G., Bohannon, J., Travisano, M., and Rainey, P.B. (2002) Adaptive divergence in experimental populations of Pseudomonas fluorescens. I. Genetic and phenotypic bases of wrinkly spreader fitness. Genetics 161: 33-46.

Steinberger, R.E., and Holden, P.A. (2005) Extracellular DNA in single- and multiple-species unsaturated biofilms. Appl Environ Microbiol 71: 5404-5410.

Tielen, P., Strathmann, M., Jaeger, K.E., Flemming, H.C., and Wingender, J. (2005) Alginate acetylation influences initial surface colonization by mucoid Pseudomonas aeruginosa. Microbiol Res 160: 165-176.

Ude, S., Arnold, D.L., Moon, C.D., Timms-Wilson, T., and Spiers, A.J. (2006) Biofilm formation and cellulose expression among diverse environmental Pseudomonas isolates. Environ Microbiol 8: 1997-2011.

Webb, J.S., Lau, M., and Kjelleberg, S. (2004) Bacteriophage and phenotypic variation in Pseudomonas aeruginosa biofilm development. J Bacteriol 186: 8066-8073.

Weber, H., Pesavento, C., Possling, A., Tischendorf, G., and Hengge, R. (2006) Cyclic-di-GMP-mediated signalling within the sigma network of Escherichia coli. Mol Microbiol 62: 1014-1034.

West, S.E., Schweizer, H.P., Dall, C., Sample, A.K., and Runyen-Janecky, L.J. (1994) Construction of improved Escherichia-Pseudomonas shuttle vectors derived from pUC18/19 and sequence of the region required for their replication in Pseudomonas aeruginosa. Gene 148: 81-86.

Whitchurch, C.B., Tolker-Nielsen, T., Ragas, P.C., and Mattick, J.S. (2002) Extracellular DNA required for bacterial biofilm formation. Science 295: 1487.

Windgassen, M., Urban, A., and Jaeger, K.E. (2000) Rapid gene inactivation in Pseudomonas aeruginosa. FEMS Microbiol Lett 193: 201-205. 